\title{
Quem falou que idosa só fica em casa?
}

\author{
Who said the elderly only stay at home? \\ ¿Quien dijo que anciana solamente se queda en casa?
}

\author{
Mariana Tereza Monferdini Ruoco'; Ana Cristina Passarella Brêtas ${ }^{\text {II }}$ Elisabeth Niglio de Figueiredo III
}

\begin{abstract}
RESUMO: O Brasil envelhece e sua população traz consigo não apenas demandas especiais de serviços públicos e de investimentos, mas modificações nas formas de olhar a vida, nos relacionamentos entre as pessoas e a cultura. Este estudo teve o objetivo de compreender o significado de participação social para os idosos que frequentam um centro de convivência. É um estudo de caso qualitativo, desenvolvido em um centro de convivência para idosos, no ano de 2012, na cidade de São Paulo. Foram entrevistadas nove idosas. As narrativas foram trabalhadas à luz dos eixos temáticos: significado de ser idoso; morar no bairro; participação no centro de convivência; dificuldades de participação; e participação social. Grande parte das entrevistadas não se sente idosa e todas participam de diversas atividades. O idoso atual está conquistando seu espaço na sociedade de maneira diferente, garantindo seus desejos e superando o comprometimento da capacidade funcional das mais diversas formas. Palavras-Chave: Envelhecimento; idoso; participação social; enfermagem.
\end{abstract}

\begin{abstract}
Brazil is aging and its population embodies not only special demands for public services and investments, but changes in ways of looking at life, in relationships between people and culture. This qualitative case study sought to understand the meaning of social participation to older adults who attend a community center. Nine elderly women who frequent a community center for the elderly in the city of São Paulo were interviewed in 2012. Their narratives were analyzed in view of the themes: the meaning of being old; living in the neighborhood; participation in the community center; difficulties in participation; and social participation. Most of the women did not feel old and all participated in several activities. Today's older adults are securing their place in society in a different manner, realizing their wishes and overcoming impaired functional capacity in all manner of ways. Keywords: Aging; older adults; social participation; nursing.
\end{abstract}

RESUMEN: El Brasil envejece y su población trae consigo no solo demandas especiales de servicios públicos y de inversión, pero cambios en las formas de ver la vida, en las relaciones interpersonales y la cultura. El objetivo fue comprender el significado de la participación social para ancianos que frecuentan un centro de convivencia. Estudio cualitativo, desarrollado en un centro de convivencia para ancianos en la ciudad de São Paulo-Brasil, en 2012. Fueron entrevistadas nueve ancianas. Los relatos fueron elaborados a la luz de ejes en los temas: el significado de ser anciano; vivir en el barrio; la participación en el centro de convivencia; dificultades de participación; y participación social. Gran parte de las entrevistadas no se siente anciana y todas participan en diversas actividades. El anciano está conquistando su espacio en la sociedad de manera diferente, asegurando sus deseos y superando el deterioro de la capacidad funcional de diversas formas.

Palabras Clave: Envejecimiento; anciano; participación social; enfermería.

\section{INTRODUÇÃO}

O Brasil envelhece e sua população traz consigo não apenas demandas especiais de serviços públicos e de investimentos, mas modificações nas formas de olhar a vida, nos relacionamentos entre as pessoas e a cultura. O aumento da proporção de idosos já é visível nos diferentes ambientes sociais e grande parcela dos velhos contemporâneos não se limita mais às suas residências ou a instituições de longa permanência, ocupando, um espaço de destaque na sociedade ${ }^{1}$. No país proliferam programas relacionados à participação social voltados para os idosos como os grupos de con- vivência que encorajam a busca da auto-expressão e a valorização de identidades, podendo ser vivido coletivamente no tempo, maneira e individualidade de cada idoso².

A escolha do tema participação social dos idosos decorreu da vivência da pesquisadora principal deste trabalho em estudar e morar em um bairro onde circulam muitos universitários, e por observar que, nas ruas circunvizinhas à Universidade, os estudantes estão mesclados com muitos idosos - fato considerado intrigante. Desse modo, decidimos investigar, por meio de

\footnotetext{
IEnfermeira. Residente em Enfermagem no Programa Saúde do Adulto e do Idoso na Universidade de São Paulo, Hospital Universitário da Universidade de São Paulo. Brasil.E-mail: maruoco@yahoo.com.br.

IIEnfermeira. Socióloga. Professora associado da Escola Paulista de Enfermagem da Universidade Federal de São Paulo, Departamento de Administração e Saúde Coletiva. São Paulo, Brasil. E-mail: acpbretas@unifesp.br.

IIIEnfermeira. Farmacêutica. Professora adjunto da Escola Paulista de Enfermagem da Universidade Federal de São Paulo, Departamento de Administração e Saúde Coletiva. São Paulo, Brasil. E.mail: elisabeth.niglio@unifesp.br.
} 
um trabalho científico, como se dá a participação social dessa população, nessa região. $\mathrm{O}$ objetivo do estudo foi compreender o significado de participação social para os idosos que frequentam um centro de convivência.

\section{ReVisÃo DE LITERATURA}

O envelhecimento da população mundial é crescente, o número de pessoas idosas, no mundo, é cerca de 600 milhões e este total dobrará até 2025 chegando a dois bilhões em 20503,4

Em 1988, direitos de cidadania específicos para os idosos foram incorporados à Constituição brasileira. A família, a sociedade e o Estado têm o dever de amparar as pessoas idosas, assegurando sua participação na comunidade, defendendo sua dignidade e bem-estar e garantindo-lhes o direito à vida ${ }^{5}$. Também, o Estatuto do Idoso é o reconhecimento social dos direitos desse grupo. Salienta a necessidade de garantir a participação desta população na vida familiar e comunitária ${ }^{5}$.

A participação social, fundamental na autonomia dos idosos, é um dos quesitos estimulados no Guia Global das Cidades Amigas do Idoso descrevendo-a como: oportunidades e atividades financeiramente acessíveis; diversidade de eventos e atividades para diferentes interesses; locais e ambientes adequados; divulgação de atividades e eventos que realmente atinjam os idosos, estimulação da participação e combate ao isolamento com convites individuais, se necessário, integrando gerações, culturas e comunidades ${ }^{6}$.

\section{Metodologia}

Trata-se de um estudo de caso social, onde o pesquisador apreende o fenômeno abordado, a partir da exploração intensa de um ou vários casos, dentro do seu contexto de vida? . Foi aprovado pelo Comitê de Ética em Pesquisa da Universidade Federal de São Paulo (CEP 1868/11), todos os procedimentos éticos inerentes aos estudos dessa natureza foram realizados.

Foi realizado em um centro de convivência para idosos, em São Paulo, que conta com cerca de 130 conviventes semanais. Fizeram parte desta pesquisa nove idosas denominadas Ágata, Ametista, Cristal, Diamante, Esmeralda, Jade, Pérola, Rubi e Safira; não houve critério de exclusão por parte da pesquisadora, contudo, no momento das entrevistas, somente as mulheres estavam presentes no Centro de Convivência. Concordaram em participar do estudo após esclarecimentos do objetivo, método, formas de divulgação do trabalho e anonimato, assinando o Termo de Consentimento Livre e Esclarecido.

Os dados foram coletados por meio da técnica da entrevista, gravadas e transcritas pela pesquisadora, assegurando o sigilo acordado com as narradoras. Para sua realização, foi utilizado um instrumento com questões norteadoras, que versaram a identificação das participantes; significados de participação social e participação no centro de convivência; sentidos de ser idoso e morar na região do Centro de Convivência. As entrevistas permitiram um diálogo livre entre a pesquisadora e as entrevistadas.

Os dados foram analisados levando em conta a necessidade de delinear possíveis implicações teóricas de seus achados, considerando as classes de eventos que poderiam ser representativos para responder ao objetivo da pesquisa? ${ }^{7}$ Emergiram da análise dos depoimentos os seguintes eixos temáticos: significado de ser idoso; morar no bairro; participação no centro de convivência; dificuldades de participação; e participação social.

\section{Resultados e Discussão}

Ágata e Ametista no momento da entrevista estavam com 65 anos, a primeira insistiu para participar da pesquisa, apesar de estar com pressa, e a segunda, já com tempo para a conversa, contou sobre sua formação e da filha que atua na área da saúde, além de falar com orgulho da sua terra natal:

\section{[... e eu não sou daqui de São Paulo eu sou de Belém. (Ametista)}

Cristal, com 64 anos, participa do Centro de Convivência há menos de um ano e mostra um grande interesse em ensinar e aprender. Diamante tinha 69 anos e aparentava ser muito mais jovem, ela mesma reconhece.

\section{[...] não me sinto idosa, sou bem vaidosa, ninguém dá a minha idade. (Diamante)}

Esmeralda, 75 anos, contou sobre seu neto, disse que ele não gostava muito de prosear com ela. A senhora Jade com 76 anos se mostrou muito ativa e participativa. Pérola, 77 anos, estava agitada, ansiosa e falou em diversos momentos sobre a violência da sociedade. Rubi, 79 anos, referiu um incômodo em relação aos idosos que ficam restritos em casa. Por fim, Safira, com 87 anos, foi muito serena durante toda a conversa, falou inúmeras vezes sobre a família.

\section{Ser idoso}

A velhice é um fenômeno biológico, psicológico e social, portanto, não é estático, sendo o resultado e o prolongamento do processo de envelhecimento, que em si é irreversível ${ }^{8}$.

Ser idosa é uma sequência da vida. A gente tem que aceitar e viver do melhor modo possível. (Rubi)

\section{[... consequência de tudo que a gente viveu. (Esmeralda)}

Grande parte das entrevistadas não se sente idosa. Estudos têm ressaltado que envelhecer permeia mudanças, portanto, saber lidar com os ganhos e perdas, assimilar e não negar este processo, adaptando-se e buscando novas aquisições, torna saudável o ser idoso ${ }^{9-13}$. 
O envelhecimento é um fenômeno natural, envelhecemos porque vivemos, muitas vezes sem nos darmos conta disso. O ser humano vive, em geral, com sua atenção voltada para o futuro ou para o passado. A velhice nos faz pensar que o futuro pode não existir, e que o frequente apego ao passado, pode comprometer a vida presente. Acreditamos que o envelhecimento é um processo no qual a velhice constitui a última etapa, portanto, a percepção de estar-no-mundo, nos remete à reflexão de que o humano precisa incorporar, nos seus hábitos, envelhecer todos os dias?

Ser idosa é uma contingência da vida, às vezes a gente não toma muita consciência disso, porque a cabeça da gente não acompanha a idade. Eu sei que tenho 65 anos, mas a minha cabeça não é de 65. (Ametista)

Se sentir idoso, para muitas delas significa se sentir incapaz. É na dor do corpo que a velhice é percebida, fazendo-nos acreditar que as perdas funcionais estão diretamente ligadas à percepção do envelhecimento. $\mathrm{O}$ declínio da capacidade funcional limita o desempenho das atividades cotidianas ${ }^{10-14}$.

Sinto-me muito bem disposta e faço quase todas as atividades que fiz a minha vida inteira. (Cristal)

Não me sinto idosa, me sinto jovem, dor todo mundo tem, a idade é implacável. Posso me sentir uma senhora, não uma idosa. (Diamante)

Por outro lado, Safira reconhece seus limites, percebe com clareza que na fase da vida em que se encontra precisa escolher outras atividades, adequar seu dia a dia a suas condições atuais e ressalta estar feliz. Com o passar do tempo ganhamos algumas habilidades e perdemos outras e a sabedoria está em utilizar as habilidades adquiridas para superar as que foram perdidas.

O que eu faço agora é coisa mais leve um pouquinho por causa da minha idade. Acho que abuso um pouquinho, para esta idade. E então, o que eu faço aqui (no Centro de Convivência), fico feliz, está tudo bem. (Safira)

Em cada significado do ser idoso, para estas mulheres, aprendemos a sabedoria com que lidam com o processo de envelhecimento. Percebem que envelhecer é inevitável e fazem desta experiência, uma vivência prazerosa. Pensamos que parte significativa de nossa sociedade não está pronta para viver a velhice, pois, não se prepara para envelhecer durante toda a vida.

\section{O bairro}

A raiz, imprescindível à planta, além de fixá-la, absorve do solo os nutrientes necessários à sobrevivência. Com os seres humanos não é diferente, a noção de enraizamento, confere sentido à existência. Dessa maneira, a vida no bairro está impregnada de sentidos e sentimentos, conforme pode ser observado nas narrativas a seguir.
Não troco por bairro nenhum, por bairro nenhum! Estou acostumada aqui. (Rubi)

Ah! Morar, aqui, neste bairro; olha, eu praticamente morei [aqui] toda a minha vida. (Cristal)

O bairro é maravilhoso. (Diamante)

Elogiam o bairro dizendo que tem tudo, mas o que é tudo? Pode ser o contrário de nada, ou ainda, para cada faixa etária tem um sentido. Elas referem ao bairro como ambiente com todos os recursos necessários para viverem.

O local que eu moro é muito, muito bem localizado. Nós temos tudo que precisamos neste bairro. (Ágata)

Tem condução, tem tudo! (Rubi)

Gosto daqui, principalmente deste lugar, aqui tem tudo: supermercado, farmácia, dentista. (Pérola)

[...] morar aqui para mim é bom, o bairro é bom, tem tudo. (Cristal)

O suporte social decorrente do relacionamento constante com amigos protege da perda funcional, mostrando a importância das relações sociais e afetivas, durante o envelhecimento, especialmente, as de amizade $^{9-11}$. O desenvolvimento de uma velhice com qualidade permeia a sociedade em que o indivíduo está inserido, além do estilo de vida que ele adota.

Tenho amizade com todos, padaria, supermercado, farmácia e mais este Núcleo que é tudo de bom [...]. (Ágata)

Minha filha se aposentou, ela queria um lugar mais sossegado e procuramos um lugar e como nós temos amigos aqui [...] para mim foi ótimo morar aqui. (Safira)

Este bairro para mim é como se fosse da minha terra, é uma coisa familiar.. (Ametista)

Considerando a singularidade de cada ser, a partir das vivências individuais, a senhora Ametista diz achar o bairro pacato e calmo, já a senhora Pérola refere gostar do bairro apesar de achá-lo inseguro.

É um bairro ainda pacato e bem calmo. (Ametista)

[...] apesar de que tem muito assalto, também, ainda mais com a delegacia aqui perto, o que tem é mais roubo de carro. (Pérola)

\section{O centro de convivência}

A participação no centro de convivência para todas as idosas é gratificante e prazerosa. Estes centros idealizados com objetivos, atividades e propostas diferenciados para esta população, com espaços de lazer, cultura e condicionamento físico, propiciam formas de empoderamento e cidadania no cotidiano dessas pessoas ${ }^{12}$.

É importante para mim, adoro aqui. É fora de série, estou aqui desde que inangurou. (Pérola)

Participo de várias coisas aqui. (Esmeralda) 
Elas referem participar de diferentes atividades, exercendo um poder de decisão em relação ao que gostam ou não, além de atribuírem significados diferentes às atividades e estarem no centro de convivência.

É para uma higiene mental. [...]. A yoga é um relaxamento. (Rubi)

Porque tudo que eu tinha que fazer aqui, bijuterias, artesanato, cozinha, dança... Tudo eu participo. (Safira)

Participar do centro de convivência fortalece um processo de gestão da velhice, valorizando e respeitando saberes acumulados no decorrer da vida. Propostas de políticas de ação, direcionadas ao idoso, favorecem o surgimento de espaços sociais significativos, possibilitam abertura de ambientes para novas experiências vividas coletivamente, revolucionando de forma positiva a imagem do envelhecer ${ }^{10}$.

Aqui, é uma coisa mais sossegada, mas é uma coisa gostosa, porque a gente tem um grupinho, são umas seis. A gente, às vezes, vem para cá, não tem nem oficina nem nada para fazer, vem para conversar, porque já fez um relacionamento. (Ametista)

Você começa a se relacionar com as pessoas da sua idade, que têm os mesmos interesses, mesmo gosto, pode fazer uma boa troca. É uma atividade bem prazerosa. (Cristal)

Toda idade tem sua beleza, seus desafios e, medos; os obstáculos que vivemos em todas as etapas da vida são mais fáceis de serem superadas quando dividimos com pessoas que já vivenciaram a mesma situação. A troca de informações e de experiências fortalece e encoraja; quando as pessoas se agrupam, elas se auxiliam. Além disso, em grupo as pessoas são capazes de fazer coisas que sozinhas, provavelmente, nunca fariam ${ }^{10-14}$.

\section{Dificuldades de participação}

$\bigcirc$ declínio da capacidade funcional propicia ao idoso a limitação e, processualmente, a perda da capacidade de desempenhar, de forma independente, suas atividades cotidianas ${ }^{13}$. Sobre a questão de acessibilidade ao meio físico, tornar uma cidade do tamanho de São Paulo completamente adequada é um grande desafio econômico, técnico e cultural.

Ela que me traz todos os dias e me vem buscar, porque tem medo, porque as calçadas aqui são horrorosas, em todas as ruas. A gente tem medo de tropeçar, como têm muitas aqui que já caíram, já machucaram a perna. (Safira)

É fundamental que a família se reorganize, dando ao idoso suporte eficaz às suas demandas ${ }^{14}$. Por outro lado, as famílias envelhecem e temos idoso cuidando de idoso.

Sim, só que eu tenho uma mãe de 90 anos. Ela fica comigo, eu sou um pouquinho sobrecarregada. (Ágata)

Por outro lado, a família pode ser um obstáculo para que o idoso supere desafios do mundo contemporâneo, como manusear um computador de uso coletivo.
A minha filha trabalha muito com negócio de computador. Quando eu terminei o curso, aqui, falei: - sabe de uma coisa, vou fazer, aqui, outra vez; em casa não tenho chance! Vou mexer no computador dela, que tem coisas de trabalho e vou estragar o trabalho dela? Então, prefiro parar e ficar mais light! (Safira)

A participação social é mais fácil quando as oportunidades são muitas e estão perto de onde se mora.

Gostaria de poder participar mais, mas eu tenho o tempo restrito. Participo mais perto de casa, aqui é um pouco longe para mim. (Jade)

\section{Participação social}

A participação é construída a partir das transformações sociais, assim as práticas participativas evoluem de acordo com os contextos sociais. Os anos de 1990 marcam a institucionalização da consulta à população sobre o processo de formulação de projetos de desenvolvimento e de políticas públicas ${ }^{15}$. Ametista nos leva à reflexão de que é necessário ter coragem para participar de processos de mudanças.

É tomar consciência das coisas que acontecem no mundo, os problemas, as pessoas. Se manter informado das coisas erradas que a gente vê toda hora e ninguém fala nada; ninguém tem coragem de tentar de alguma forma mudar as coisas. (Ametista)

A convivência por meio de atividades desencadeia oportunidades para o desenvolvimento da criatividade e, a partir do relacionamento, eles percebem sua força social ${ }^{15-17}$.

Faz com que nos fortalecemos e crescemos mais, aqui, a gente fica mais forte com a turma, com essa troca de energia, troca de pensamento. Hoje, a nossa turma vai se reencontrar, tomar um cafezinho. (Ágata)

A participação social na velhice está relacionada à boa saúde e ao envolvimento ativo, assim fazer parte de atividades sociais e culturais na comunidade e com a família permite o exercício da autonomia, desenvolvendo uma posição que exige respeito e apoio ${ }^{16}$.

Desde que inaugurou aqui, eu frequento, o dia que dá para vir eu venho, o dia que não dá, não venho. Às vezes, saio com a minha filha, mas eu prefiro frequentar aqui, não é todo lugar que eu tenho que ir atrás dela. (Safira)

Participo de tudo que me interessa. Não gosto dessa musicoterapia. O que não gosto não participo, participo do que gosto. (Ametista)

O idoso, com maior autonomia, é capaz de traçar seus próprios caminhos, realizando seus desejos e conhecendo seus limites ${ }^{11-17}$.

Tudo que tinha que fazer aqui, bijuterias, artesanato, cozinha, dança, música, eu participo. O que faço agora é coisa mais leve, por causa da minha idade. Acho que abuso um pouquinho para esta idade. Fico feliz e tudo está muito bem. (Safira) 
A aceleração da vida urbana, que leva à diminuição dos contatos sociais dos idosos, principalmente familiar, favorece o isolamento. A consciência deste fator, a saúde e a autoestima levam os idosos a criarem estratégias individuais para buscar lugares prazerosos e com pessoas que eles se identificam.

Participação social, principalmente para nossa idade, eu acho que faz muita falta, porque se não a gente fica restrita em casa, lavando, cozinhando. (Rubi)

Hoje em dia cada um vai para um lado e a gente, com a idade da gente, fica em casa tranquila. Nem sempre, porque saio muito com minha filha, mas a maioria eu sei que é assim. (Safira)

Para as idosas, a socialização também se dá no trabalho voluntário, na ajuda. O idoso em contato com outras pessoas valoriza sua autonomia, capacidade de trabalho, além de se sentir ativo e manter suas conexões sociais.

Participação social, também, é ajudar o próximo como tem várias associações que eu ajudo. (Pérola)

Existe a participação social quando você, por exemplo, trabalha como voluntário num hospital, numa casa de idosos. Pretendo fazer isso mais tarde. (Cristal)

Tudo que eu esteja sentindo bem, em termos da minha pessoa e para as outras pessoas, também. Não só para mim. Ajudando as outras pessoas, também, e fazendo alguma coisa para o meu bem-estar. (Diamante)

Enfim, depreendemos neste estudo que a participação social para as idosas tem diferentes significados. Todas participam de alguma atividade no Centro de Convivência e também fora dele. Tal fato nos faz questionar se os idosos que frequentam os equipamentos sociais são aqueles que na fase adulta anterior ao envelhecimento já tinham a prática da participação social.

Como enfermeiras, também estamos preocupadas com aqueles idosos que se confinam - ou são confinados - em suas casas, entendendo que a qualidade do envelhecimento tem relação direta com a qualidade de saúde e consequentemente de vida. A participação em atividades socioculturais contribui para que os idosos permaneçam mais ativos e saudáveis física e intelectualmente ${ }^{17}$, contudo está prática precisa ser desenvolvida no curso da existência, não deve ser uma imposição aos velhos, visto que somos fruto das nossas trajetórias individuais de vida.

\section{ConClusão}

Este estudo possibilitou a reflexão sobre o significado de participação social para algumas idosas que frequentam um centro de convivência, fazendo-nos crer que estão conquistando seu espaço na sociedade de maneira diferente.

O contato com essas idosas possibilitou indagações práticas e teóricas. Alteraram nossos pensamen- tos de que idosos fazem poucas atividades ou gostam de ficar em casa, pelo contrário, as entrevistadas ensinaram que a participação social resulta da predisposição de estabelecer contato, construir relações com outras pessoas. Fomos estimuladas a trazer para a Universidade, em particular para o Curso de Gradução de Enfermagem, reflexões sobre o papel do enfermeiro como educador para o envelhecimento saudável, bem como sobre como este profissional está se preparando para a própria velhice.

Finalmente, salientamos que é necessário disseminar a ideia de que a participação social contribui para a qualidade de saúde individual e coletiva, portanto deve ser estimulada em todo o curso da vida, entendendo que o envelhecimento é um processo e a velhice a etapa final deste caminhar. Resta-nos entender o fenômeno do envelhecimento, garantindo o direito participativo, e potencializar os desejos individuais de cada pessoa.

\section{REFERÊNCIAS}

1.Justo JS, Rozendo AS, Correa MR. O idoso como protagonista social. A Terceira Idade. 2010; 21:30-53.

2.Veras R. Envelhecimento populacional contemporâneo: demandas, desafios e inovações. Rev Saude Publica. 2009; 43:548-54.

3.United Nations. Department of Economic and Social Affairs. Population Division. Population Ageing 2006 [on-line]. New York: United Nations; 2006. [cited in 2014 Jan 12] Disposible in: http://www.un.org/esa/population/publications/ageing/ageing2006.htm.

4.Instituto Brasileiro de Geografia e Estatística. Pesquisa Nacional por Amostra de Domicílios - Síntese de Indicadores 2009. Rio de Janeiro: Ministério do Planejamento, Orçamento e Gestão; 2010.

5.Ministério da Saúde (Br). Estatuto do Idoso. Brasília (DF): Editora MS; 2013.

6.Organização Mundial da Saúde. Guia global: cidade amiga do idoso. Brasília(DF): Publicações da Organização Mundial da Saúde; 2008.

7.Becker HS. Métodos de pesquisa em ciências sociais. 2a ed. São Paulo: Hucitec; 1994.

8.Beauvoir S. A velhice: o mais importante ensaio contemporâneo sobre as condições de vida dos idosos. Rio de Janeiro: Nova Fronteira; 1990.

9.Brêtas ACP, Marcolan JF, Rosa AS, Fernandes FSL, Raizer MV. Quem mandou ficar velho e morar na rua? Rev esc enferm USP. 2010; 44:476-81.

10.Debert GG. A reinvenção da velhice: socialização e processos de reprivatização do envelhecimento. São Paulo: EDUSP/FAPESP; 2004.

11.D'Orsi E, Xavier AJ, Ramos LR. Trabalho, suporte social e lazer protegem idosos da perda funcional: estudo epidoso. Rev Saude Publica. 2011; 45:685-92.

12.Costa FG, Campos PHF. Práticas institucionais e representações da exclusão na terceira idade. In: Campos PHF, Loureiro MCS, organizadores. Representações sociais e práticas educativas. Goiânia: EdUCG; 2003. p.187-207. 
13.Neri AL. Envelhecer num país de jovens: significados de velho e velhice segundo brasileiros não idosos. Campinas (SP): Editora da Universidade de Campinas; 1991.

14.Vieira EB. Manual de gerontologia: um guia teóricoprático para profissionais, cuidadores e familiares. Rio de Janeiro: Revinter; 2004.

15.Milani CRS. O princípio da participação social na gestão de políticas públicas locais: uma análise de ex- periências latino-americanas e européias. Revista de Administração Pública. 2008; 42:551-79.

16.Flosi C. Envelhecer na cidade: $1^{\text {o }}$ de outubro de 2010 - Dia Internacional do Idoso. Cadernos de Cidadania (São Paulo). 2010; 4: 8-17.

17.Peregrino AAF, Schutz V, Marta CB, Pereira ACA, Silva GP, Nogueira LC. Buscando a inserção dos idosos nas ações de promoção social e de saúde. Rev enferm UERJ. 2012; 20:513-8. 